Revista Iberoamericana, Vol. LXXVII, Núms. 236-237, Julio-Diciembre 2011, 849-863

\title{
PROTONOVELAS ROMÁNTICAS EN LA HISTORIA ANTIGUA DE FRANCISCO JAVIER CLAVIJERO
}

\author{
POR \\ LINDA EGAN \\ University of California-Davis
}

A la Historia antigua de México (1780-1781) de Francisco Javier Clavijero se le ha llamado la narración más completa, sucinta y elegante de la vida del pueblo azteca antes de la llegada de los europeos y luego de la conquista de este pueblo entre 15191520. ${ }^{1}$ Un estudioso contemporáneo la considera la primera y más auténtica historia de México escrita por un mexicano (Blanco 195-96); en la tradición de la "epistemología patriótica” (Cañizares-Esguerra 236), al jesuita exiliado le permitieron las lecturas enciclopédicas, la memoria incomparable y el intelecto moderno para sintetizar y ordenar coherentemente lo que en dispersas crónicas anteriores había sido la transmisión a trozos de hechos de significancia limitada en sí o bien de fantasías que quedaban sin el correctivo del juicio comparativo de una mentalidad crítica. Esta valoración de la clásica obra histórica de Clavijero es justa, sin lugar a dudas, pero vale advertir al mismo tiempo que su manipulación diestra de cronología, diálogo, punto de vista y descripción señalan al escritor como un artista narrativo cuyos logros verbales -cuyo discurso heteroglótico, hecho de múltiples estrategias novelescas-difícilmente confinan su Historia al género historiográfico.

Ahora bien, para Walter Mignolo, el que Clavijero se sirva de técnicas ficcionalizadoras no disminuye la solidez de su reclamo al género historiográfico, ya que el autor produjo su texto y sus lectores lo recibieron dentro de los preceptos del momento como un libro de historia (362-63). Sin duda, la intención autorial es importante (Hirsch 71-89; Jauss 189-91), pero no es exclusivamente determinante. Que un autor prometa decir la verdad sí restringe "el juego libre del intentio lectoris" (Collini 9, mi traducción), o lo que puede tomarse por la imposición irrelevante o arbitraria de un significado sobre un texto (Lanser 72), pero esa promesa autorial no constituye de por sí prueba suficiente de que

\footnotetext{
1 Clavijero escribió su gran crónica en español, en Boloña, lo tradujo él mismo al italiano y la publicó con el título de Storia Antica del Messico. La primera edición en español, de 1826, fue una traducción de la traducción en italiano del manuscrito original en español. Éste, hallado a mediados del siglo xix en México, fue publicado en 1945. Véase Stoll 173-74.
} 
el texto producido pertenezca a uno u otro género. En el caso de la "promesa" de que la Historia de Clavijero forme parte sólo y únicamente del género historiográfico, habría que considerar, por ejemplo, la intensidad y frecuencia de elementos que se acumulan para efectuar "una 'literaturización' gradual del discurso; discurso que asume...los rasgos de la amplificatio satírica” (Pupo-Walker 66).

En fin, coincido con Mignolo a medias; la Historia de Clavijero figura, como he ya señalado, entre los récords más fidedignos y completos de México antes y durante la conquista. Pero al mismo tiempo, por el efecto de su lenguaje y lo que Hayden White llama el contenido de la forma”, ocupa un nuevo territorio protoficcional, a la vez que lo prepara para escritores como Servando Teresa de Mier, ${ }^{2}$ Lizardi, Echeverría, Prieto y los demás románticos que nacionalizan a sus países escribiendo.

La crítica tradicionalmente adscribe al Periquillo Sarniento (1816) de José Joaquín Fernández de Lizardi el honor de ser la primera verdadera novela de México (Brushwood 1) y, mientras este análisis de la Historia de Clavijero no pretende desplazar a Lizardi, sí ofrece una lectura nueva de la obra al señalar que Clavijero escribe con un lenguaje de tal forma doble, o híbrido (entre empírico e imaginativo), que tiende hacia el “double-languagedness" (Bakhtin, Dialogic 356) que indica un discurso ficcionalizado, la hibridización e interdiscursividad que Bakhtin denomina como típica de la índole carnavalizada de la novela (Problems 118-19). Este modo nuevo de mirar la obra magistral de Clavijero -y de la historia literaria de México- puede ajustar nuestra visión de obras como La hija del judío (1848) de Justo Sierra O’Reilly, por ejemplo. ${ }^{3}$

Tan insistente es el juego literario del discurso clavijeriano, tan obvio llega a ser su carácter novelesco, tanto en la primera parte (la historia medieval del México prehispánico), como en la segunda (el relato renacentista de la conquista), que en muchos momentos nos hace pensar en un romance histórico del género de Ivanhoe, por el escocés Sir Walter Scott. Claro, la novela de Scott no se publica hasta 1819, a tiempo para influir a menudo en las novelas históricas de Hispanoamérica y México (Brushwood 5; Castro Leal xiii). Desde esta perspectiva, el libro de Clavijero aparece bien avant la lettre en el estilo "sublime" e incluso gótico atenuado de elementos realistas (Walsh 31-37; Auerbach 441), el cual caracteriza la novela histórico-romántica. En técnica y

2 Véase, por ejemplo, Egan, “Servando Teresa de Mier”.

3 Antonio Castro Leal afirma que con esta novela escenificada durante la colonia Sierra O’Reilly inicia la novela histórica de México (xvii). En realidad, uno podría decir que otra novela, publicada anónimamente en 1826 acerca de la conquista de México (Jicotencal), iniciará la tradición del romance histórico en México. Sin embargo, como demuestro en este estudio, la Historia de Clavijero puede verse en el territorio que será el México independiente como el primer paso hacia la creación de la novela romántico-histórica. Y su obra, en principio, surge de la tradición clásica: Scholes y Kellogg sugieren que la novela histórica nace con el historiador griego Xenófono, quien deliberadamente mezcla historia y ficción en su Cyropedia (67).

Revista Iberoamericana, Vol. LXXVII, Núms. 236-237, Julio-Diciembre 2011, 849-863 ISSN 0034-9631 (Impreso) 
temática, ésta se confecciona de conocidas dualidades convencionales (bien vs. mal, héroe vs. malvado), los procesos obligatorios (viaje peligroso, rescate de la doncella hermosa, promesa de felicidad futura, establecimiento de un nuevo orden social) -todo levemente parodiado por la inclusión de villanos heroicos, un héroe imperfecto, y así por el estilo. Scott se vale de tales elementos al construir su novela histórico-romántica, mejor ejemplificada por la Ivanhoe de 1819 (Sroka 645-53); son los mismos elementos que componen el discurso de la Historia antigua de México de Clavijero en $1780 .{ }^{4}$

Cuarenta años después, Scott consagrará el género histórico-romántico al lanzar novelas entretenidas que no obstante critican la sociedad y el gobierno ingleses por-para nombrar dos problemas- su maltrato de los judíos del siglo trece ${ }^{5}$ y por ser hipócritas acerca del carácter mixto de su linaje céltico-normando-sajón (para no mencionar el druídico). ${ }^{6}$ Ya en 1780 un exiliado mexicano en Italia, al escribir la historia de su nación imaginada principalmente desde la memoria, se aproxima a aquel género al dramatizar las inclusiones y exclusiones del linaje nacional de la sociedad tolteca-chichimeca-mexica que el español Hernán Cortés conoce al invadir su territorio en 1519, y luego al ilustrar los procesos de conquista, conversión, transculturación, genocidio y acomodación sociopolítica que norman las bases de un nuevo linaje nacional que pronto inventa otras inclusiones y exclusiones.

Quizás por un exceso de prudencia, al demostrar claramente el parentesco entre la Historia verdadera de la conquista de la Nueva España de Bernal Díaz y lo que en los siglos xx y xxi será en la nueva novela histórica un intento de reescribir la historia desde la ficción (Estrada 149-88), Oswaldo Estrada asegura que "[n] e estamos buscando padres a la literatura latinoamericana ni transformando el espacio colonial para que éste exprese aquello que queremos que nos diga sobre el presente” (43). De hecho, Estrada hace precisamente eso en La imaginación novelesca, Bernal Díaz entre géneros y épocas (2009), y es lo que hago ahora con esta lectura de Clavijero: sí hay, tanto en Bernal como en Clavijero y hasta cierto punto en Garcilaso el Inca como en Acosta y

4 Un practicante aún más temprano de este tipo de realidad y ficción mezclados es el cronista Bernal Díaz del Castillo, quien también va en contra de la filosofía ortodoxa que resiste ver en un texto historiográfico al mismo tiempo su valor y forma empíricos y su mérito como "artefacto propiamente literario" (Estrada 20). En un estudio literario de Bernal, Oswaldo Estrada enumera elementos novelescos que jalan la crónica del viejo conquistador hacia el lado artístico-ficcionalizador: “[...] un lenguaje dialógico con características novelescas, el delineamiento de personajes multidimensionales, ciertos indicios de novelización del tiempo y el espacio, la creación del suspenso en un ámbito que nos da la sensación de ser doméstico y privado, así como la perspectiva omnisciente de un narrador que participa en la diégesis y nos entrega la totalidad de una época histórica que parece construirse al momento de la lectura” (20).

5 Los ingleses expulsan a los judíos de su territorio en 1290, la primera nación europea que lo hace.

6 Ragussis observa que, con las ruinas de la cultura druídica descritas en Ivanhoe, Scott recuerda a los ingleses del xIx que su linaje nacional incluye una época de sacrificio humano (193). Sobre los druidas del 1 a.C. y los primeros siglos d.C., véase Green, especialmente 71-89, sobre sus ritos sacrificiales.

Revista Iberoamericana, Vol. LXXVII, Núms. 236-237, Julio-Diciembre 2011, 849-863
ISSN 2154-4794 (Electrónico) 
más adelante en Servando Teresa de Mier (entre otros cronistas de Indias), "padres” escritores de crónicas de una literatura anunciada en técnicas y efectos narrativos que rebasan los límites convencionales del género historiográfico y de la intención explícita de sus autores.

En el caso ante nosotros, la Historia antigua de Clavijero, mientras el escritor jesuita no deja de informar precisa y detalladamente, tampoco resiste la tentación de fabular. El resultado es un relato "sublime" que el lector consume como si fuera una novela histórico-romántica semejante a la que, desde la segunda década del XIX, se iría elaborando en la región nuevamente nacionalista de América del Sur y México.

Aludiendo a El Periquillo Sarniento, Fernando Unzueta nos recuerda que la función de la novela decimonónica en Hispanoamérica es educar al público, crear una comunidad y participar en el proyecto de nación; discursivamente, es marcadamente didáctica, con un contenido político y social que incluye formas extra-literarias; debe caracterizar a todas las clases sociales y a las mujeres tanto como a los hombres (21-40). Un lector de Clavijero consta que todo esto describe el nuevo espacio discursivo que estrena el cronista en su gran obra. Aparte, el sentimentalismo que falta en el discurso picaresco del Periquillo abunda en Clavijero. La Historia antigua, si la viéramos como novela, y la de Lizardi pertenecerían a distintos subgéneros.

La historia nacional que el jesuita narra casi dos siglos después de la época bélica del descubrimiento y conquista comienza con la llegada de los toltecas al Valle de Anáhuac. ${ }^{7}$ Analizamos el discurso con dos avisos previos en mente: que, (1) aunque Clavijero niegue haber procurado escribir con elegancia o belleza, revela su interés por lograr un estilo agradable y natural (xxi), (el cual excede con frecuencia e impacto novelesco, como veremos), y (2) elige secuestrar casi toda su documentación y argumentación académicofilosófica hasta el final de su historia para no estorbar la fluidez de su narración; si hubiera puesto la documentación "en el cuerpo de la Historia, habría sido necesario interrumpir el hilo de la narración con disputas espinosas,” dice al principio de la segunda disertación (443). ${ }^{8}$ Esta decisión estructural y estilística resulta cuasi-genérica: salvo por alguna

\footnotetext{
7 No incluye Teotihuacan (c. 200 a.C.-650 d.C.) ni a ningún otro pueblo pre-clásico o clásico anterior a los toltecas (c. 968-1156), principalmente porque, como explica en la primera de sus disertaciones al final (424-42), no existe a su alcance documentación más fidedigna que la Biblia (la Torre de Babel, el Diluvio) para trazar el origen de la población de México más allá del pueblo de Tula además ha podido consultar virtualmente todo lo que se había escrito sobre México en su momento -el Códice Ramírez, Cortés, Gómara, Bernal, Sahagún, Torquemada, Acosta, Boturini, Tezozómoc, Ixtlilxóchitl, et al. y también los códices pintados que habían sobrevivido el celo destructivo de los misioneros-. Véase su bibliografía anotada, "Noticia de los escritores de la historia antigua de México," siglos XVI, XVII y XVIII, más pinturas, en el prólogo del autor (Clavijero xxv-xxxvii).

8 La ficción, "in its highest sense involves ordering and shaping for an aesthetic end” (Scholes y Kellogg 73). Más recientemente, Hayden White nos recuerda que "narrative should be considered less as a form of representation than as a manner of speaking about events, whether real or imaginary” (2). Es decir, en

Revista Iberoamericana, Vol. LXXVII, Núms. 236-237, Julio-Diciembre 2011, 849-863
ISSN 2154-4794 (Electrónico)
} 
que otra nota a pie de página, la Historia se presenta como un relato, una narración que parece fábula. La primera parte, con su “tiempo de aventura” y encuentros cuasi-míticos entre tribus y héroes le dan un carácter que Bakhtin viera como romance de tipo griego (Dialogic 84-258), se lee sin costura hasta el momento cuando llegan los españoles. En una cesura Clavijero inserta por separado información sobre la religión mesoamericana y otras costumbres de la región (evidencia del Otro que los europeos confrontarán). Al retomar el hilo de la narración, ahora para detallar los sucesos épicos de la conquista, parte de los primeros viajes españoles por las costas de México. La fábula que resulta parece un romance renacentista con precoces atisbos románticos.

La Historia se presenta como una narración en tercera persona, como sería de esperar de un documento empírico, pero la voz es en realidad de la primera persona mixta del cronista, lo cual se nota cuando de vez en cuando Clavijero revela su "yo" abiertamente. Lo hace, por ejemplo, cuando intercala un comentario para disputar la doctrina demonológica, al narrar la llegada de los chichimecas mexicas a Mesoamérica (66). Lo que del todo no sería de esperar a estas alturas, tantos siglos después de Herodoto y Tácito, es hasta qué punto Clavijero se da el lujo de la omnisciencia y, efectivamente, de inventar lo que sus figuras históricas están sintiendo o pensando. He indicado en otro momento que la postura narrativa del cronista es un yo privilegiado, aunque desde el punto de vista de un nuevoperiodista estadounidense como Tom Wolfe o un cronista mexicano de la Generación del ’68 como Carlos Monsiváis, no inventan, exactamente, lo que sus personajes piensan, sino que recrean la interioridad ajena en base de un reportaje a fondo. ${ }^{9}$ En el caso de Clavijero, sería imposible hacer entrevistas largas con sus “personajes.” Además, para el siglo XviII, el uso de la clásica arenga inventada por los historiadores grecorromanos menguaba entre historiadores letrados, justo cuando entre ficcionalistas estaba entrando en uso el punto de vista sustitucionario o dual (Hernadi 32-43). Notable asimismo es la numerosa y continua cantidad de arengas que Clavijero mete en boca de estas figuras históricas, arengas no tan largas como la costumbre las indicara, ni colocadas en ocasiones siempre ceremoniales; las de Clavijero son regularmente breves a manera de diálogo y su propósito es comunicar información, sentimientos y planes. Es decir, el uso de la “arenga” es inmediato y contingente, entre individuos y respondiendo a las circunstancias fluidas de la vivencia de los personajes y la acción del argumento de la Historia.

nuestra recepción de un texto, cómo el discurso se ha confeccionado resulta tan o tal vez más relevante que lo que comunica. De ahí que White elabore su teoría sobre el contenido de la forma en The Content of the Form: Narrative Discourse and Historical Representation.

9 Sobre voz y punto de vista de los cronistas actuales, véase Egan (Carlos Monsiváis 105-31). Sobre cómo Bernal Díaz entra en la conciencia de Hernán Cortés, véase el mismo texto 107-108. En caso de consultar la traducción en español de Egan (2004), véase las páginas 177-212 (179-80 sobre Bernal y Hernán Cortés).

Revista Iberoamericana, Vol. LXXVII, Núms. 236-237, Julio-Diciembre 2011, 849-863
ISSN 0034-9631 (Impreso) 
Para ilustrar: el rey Xólotl de Tenayuca, primero de los chichimecas que llegaron después de la ruina de los toltecas, ${ }^{10}$ dramáticamente elude un plan de sus enemigos de ahogarlo en su jardín y "el rey determinó llevar adelante su disimulo y burlarse de sus enemigos. 'Yo, dijo, estaba persuadido de que mis vasallos me amaban; mas esta vez he conocido que me aman más de lo que yo pensaba'” (Clavijero 56). Primero el narrador nos permite saber qué piensa Xólotl, y luego podemos escuchar directamente lo que dice, acompañado de sus sirvientes. Más adelante en la Historia, muerto el padre del príncipe texcocano Nezahualcóyotl por obra del terrible rey Tezozómoc de Azcapotzalco, aquél considera cómo se le han robado su trono: "El dolor y la rabia que le causó aquella función, animados de su ardor juvenil, iban a precipitarlo en una acción temeraria contra sus enemigos si un íntimo privado que le acompañaba no le hubiera contenido" (84). Esta técnica bien moderna, la de la perspectiva dual, o sustitucionaria (Hernadi 41, 43), sugiere que ciertos hechos se han cumplido dentro de la narración, no por el autor sino por los personajes; ofrece además la percepción representada de Nezahualcóyotl y, más indirectamente, la de su compañero.

Un ejemplo más del empleo del estilo indirecto libre por Clavijero, entre demasiados para ilustrar en este espacio: tiempo antes de que tuviera que salir para Veracruz ${ }^{11} \mathrm{y}$ batallar contra Pánfilo de Narváez, Cortés le quita los grillos a Moctezuma y le dice que puede volver a su palacio:

El regocijo que sintió Moctezuma en esta ocasión fue proporcionado al sentimiento que le causó la ignominia de las prisiones; disipósele el temor que había concebido de que el general español atentase también a su vida, y le pareció la libertad una gracia imponderable que se le hacía; ¡tan grande era el abatimiento de ánimo en que había caído! Abrazó cariñosamente a Cortés, expresóle con singulares demostraciones su gratitud, y aquel día hizo extraordinarios favores a los españoles y a sus mismos vasallos. (347)

Aquí Clavijero ha abandonado hasta un grado insólito su deber como narrador historiográfico de mantener su distancia heterodiegética del personaje, sobre todo porque es una figura histórica de una opacidad psíquica convencional (Cohn 790). Pero Clavijero ignora este protocolo y sigue en el modo homodiegético: cuando Cortés sítiene que irse para Veracruz, y Moctezuma, al parecer sólo ahora entendiendo la enemistad entre los dos españoles, se rehusa hacer nada en contra de quien antes lo había tenido

10 Según Clavijero, se destruyó la civilización tolteca en 1052 y los chichimecas comenzaban a llegar un siglo después (51-52). Meyer y Sherman, en The Course of Mexican History, sitúan la caída de Tula en el siglo xII, alrededor de 1156 o poco después (41) y la llegada de la segunda ola de chichimecas del norte en el siglo XIII (53). El reino de Xólotl (1244-1304) establece la hegemonía chichimeca en el Valle de Anáhuac (54).

${ }^{11}$ Cortés bautizó la fortaleza La Rica Villa de la Vera Cruz.

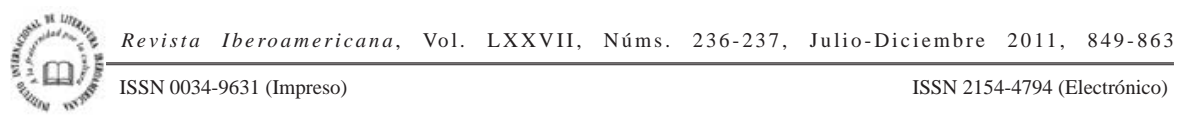


en cautiverio. He aquí lo que piensa y dice, tal como Clavijero lo revela a través de la voz sustitucionaria, la postura narrativa fundamental del ficcionalista:

Tan lejos estuvo Moctezuma de intentar cosa alguna contra Cortés, que cuando este general le fue a dar parte de su viaje a Cempoala, mostró mucha pena del riesgo a que se exponía con tan poca gente y le ofreció levantar luego un ejército para que le auxiliase en la expedición. (354)

Este tipo de narración psicológica no tiene lugar en un discurso estrictamente historiográfico; pero en la prosa “comprometida” de lo que quizá en este caso podría llamarse seudoficticia, ${ }^{12}$ está perfectamente en su sitio la caracterización de Moctezuma como víctima de lo que hoy llamamos el síndrome Stockholm. No sabría Clavijero nombrarlo, pero sí era lo suficientemente astuto como para reconocerlo; la técnica novelesca le servía para representárselo a sus lectores.

El narrador incluye en su postura abundantes comentarios que desmantelan cualquier pretensión a la objetividad historiográfica. Esto no disminuye en nada la amplitud y calidad crítica de sus conocimientos y documentación, ni de su criterio sumamente moderno. Pero en la presentación narrativa de la Historia, donde el aparato académico no estorba, Clavijero inyecta una voz que abiertamente se alía con los "buenos” de su narración y calumnia a los "malos”, con la justificación de los hechos, claro está. Con el bien contra el mal estamos en territorio del romance histórico; en Clavijero un ejemplo clarísimo es la historia épica (y romántica) de “Cómo el príncipe Nezahualcóyotl pierde y recupera su trono", o "Cómo el malvado Maxtlaton roba el trono de Texcoco y es castigado" (seudotítulos míos). El argumento contiene los elementos constituyentes de un romance; el caso que pone en juego el drama, el suspenso y actos de heroísmo que conducen al clímax y un desenlace justo: el asesinato del buen rey Ixtlilxóchitl por el malvado Tezozómoc, el "maligno" rey de los tepanecas, "monstruo de ambición, de perfidia y de crueldad” (86) que codicia el trono texcoqueño; el hijo Nezahualcóyotl que debe heredar al rey asesinado, pero que pierde su patrimonio por consecuencia de una guerra fomentada por Tezozómoc, quien regala Texcoco a Chimalpopoca, rey de México.

Lo que sigue podría sacarse y publicarse como nouvelle o cuento: intrigas políticas entre las varias cortes imperiales reconfiguradas; una trama secundaria maquiaveliana entre el hermano que hereda el trono de Tezozómoc y su hermano Maxtlaton (antagonista gótico), quien roba el trono, y hasta un portero-espía que, a medianoche, le abre la puerta a Maxtlaton para participarle noticias (86-87). Otras intrigas surgen para enredar aún más la trama compleja: hay insultos al honor de dos doncellas -la hermana de Maxtlaton y una mujer del rey mexicano- ("Fue fácil al lascivo tirano el

${ }^{12}$ Barbara Foley define la ficción de la "pseudofactual novel" como "compromised prose" (prosa comprometida) (66). Cambio la frase aquí para adaptarla a la historia de Clavijero.

Revista Iberoamericana, Vol. LXXVII, Núms. 236-237, Julio-Diciembre 2011, 849-863
ISSN 0034-9631 (Impreso) 
lograr la ocasión que deseaba para satisfacer a su pasión, sin que bastasen a contenerlo las lágrimas y los esfuerzos que empleó aquella honesta señora en defensa de su honor" [88]). Acto seguido, Chimalpopoca bendice a Nezahualcóyotl, quien rema "con suma velocidad... a Texcoco” (90), mientras el rey de México, insultado por la violación de su esposa, decide suicidarse. Bien metidos en el drama y suspenso de la historia de Nezahualcóyotl, los lectores se encuentran impactados por lo "sublime" de la prosa romántica, ya que Clavijero aquí presenta una situación histórica como una "religiosa tragedia” (89). El nuevo rey mexicano, Itzcóatl, se alía con Nezahualcóyotl, a quien el narrador alaba como "uno de los mayores héroes de la América antigua" (113) contra "el pérfido Maxtlaton” (87).

Nezhualcóyotl ha pasado ocho años desterrado de su ciudad, ya escondiéndose, ya huyendo de Tezozómoc y Maxtlaton; en un momento entra en su ciudad y está a punto de ser capturado cuando se escapa por un laberinto secreto que había mandado construir. En esto, el lector reconoce la fórmula romántica del viaje peligroso que obliga al héroe a pasar por una prueba de muerte o de askesis, la purificación por el sufrimiento (Bakhtin, Dialogic 115-17). Una y otra vez, o por la acción o por un comentario proléptico, Clavijero recluta el suspenso para aumentar el dramatismo de su relato. ${ }^{13}$

Entra ahora el primer Moctezuma de la historia mexica, héroe impaciente por lanzarse contra Maxtlaton: "Yo iré, que si por último he de morir, poco importa que sea hoy o mañana, ni puede haber mejor ocasión que la presente para morir con gloria, sacrificando mi vida al honor de mi nación” (96). ${ }^{14}$ Como eco homérico, Clavijero canta las hazañas épicas de los guerreros mexicanos y texcocanos que "se arremetieron con increíble furia” (97) contra los tepanecas. Por último, el bien vence al mal heroicamente, con "el trágico fin del tirano Maztlaton” y la restauración de la justicia al buen rey Nezahualcóyotl. Madera de leyenda -de novela romántica-, sobre todo si se considera que en esta historia de los chichimecas Clavijero ha seguido de cerca la Historia de la nación chichimeca de Fernando de Alva Ixtlilxóchitl, a cuyo héroe Nezahualcóyotl la historia popular pinta consistentemente como un nuevo David anti-sacrificial; pero en

${ }^{13}$ Dirá, por ejemplo, cuando Maxtlaton le roba el trono a su hermano: "Pero dentro de poco veremos que si la injusticia lo exaltó al trono, fue para precipitarlo de mayor altura” (88). O, en el caso de la historia de la conquista, le pondrá en la mente de Cortés, en lo peor de la lucha por su vida durante la llamada Noche Triste, "Pondera Cortés en su relación al emperador Carlos V el gran peligro en que se vio este día de perder la vida, y atribuye a extraordinaria providencia el haberla salvado entre tanta multitud de enemigos” (362). Además de crear un breve remolino de silencio y reflexión que suspende la acción vertiginosa de aquellas batallas de día y noche, Clavijero permite una risita seca al hacernos pensar en Cortés quizá arrepintiéndose de su afán por conquistar México.

${ }^{14}$ El parentesco espiritual-cultural con el corrido "La Valentina” es evidente: "Si me han de matar mañana, que me maten de una vez...” (Aunque el corrido es uno de los más famosos de la Revolución Mexicana, es realmente acerca de un amor peligroso.)

Revista Iberoamericana, Vol. LXXVII, Núms. 236-237, Julio-Diciembre 2011, 849-863
ISSN 2154-4794 (Electrónico) 
la Historia de Ixtlilxóchitl, Nezahualcóyotl hace una excepción y sacrifica a su enemigo al final de la batalla como escarnio y acto de justicia:

[...] desbarataron el ejército de Maxtla...Maxtla, que se había escondido en un baño de sus jardines, fue sacado con gran vituperio y Nezahualcoyotzin lo llevó a la plaza principal de la ciudad y allí le sacó el corazón como en víctima y sacrificio a sus dioses, diciendo lo hacía en recompensa de la muerte de su padre el emperador Ixtlilxóchitl y que aquella ciudad por ignominia suya fuese desde aquel tiempo un lugar donde se hiciese feria de esclavos. (Ixtlilxóchitl 136)

En su Historia, Clavijero elige ignorar este detalle dramático para darle otro final al "soberbio Maxtlaton" a quien "buscaban por todas partes": "Finalmente lo hallaron, y sin valerle los ruegos y lágrimas con que imploraba su clemencia, fue muerto a palos y a pedradas, y su cadáver fue arrojado en el campo para pasto de las aves” (99). Interesante que, aunque Clavijero reste el contacto personal que permite al héroe darle muerte de su mano y, más, sustraiga el elemento tremebundo del sacrificio humano, el fin que sí le proporciona al tirano reverbere con el patetismo propio del historismo romántico y es, además, una crítica secular; dejar como alimento de zopilotes al cadáver del malvado es un insulto a aquel enemigo de la justicia: no vale la muerte heroica del guerrero sobre la piedra sacrificial, sino la ignominia de una bestia tirada en un páramo. Puede ser que sólo hasta la época romántica "our own definitions of literature began to develop...[,] synonymous with the 'imaginative': to write about what did not exist was somehow more soul-stirring and valuable than to pen an account of Birmingham or the circulation of the blood" (Eagleton 18). Pero podemos hoy en la época posrromántica afirmar que lo literario no depende del tiempo histórico ni de la categoría "ficción".

Episodios "brillante[s]" (Watt 130) como el de la muerte "ignominiosa" del malvado Maxtlaton abundan en la Historia, escenas que saltan la barda historiográfica para transportar al lector a un terreno sublime de terror y horror, o bien de peligro, dolor, oscuridad, maravilla, magnificencia e hipérbole. El episodio que Clavijero titula "Sacrificio inhumano en la dedicación de su primer santuario", perfectamente gótico, agarra la atención con el juego de palabras: ¿qué sacrificio humano no es inhumano? Evidentemente, vamos a ver algo especialmente "inhumano," justo lo que el lector del romance gótico busca.

La trama: los mexicas recién establecidos en su ciudad comienzan a construir una imagen de poder, y empiezan con la táctica del terror: el sacrificio humano (71). El rey mexica le pide la mano a una de las hijas del rey de Colhuacán, para el honor del dios Huitzilopochtli. O por miedo o por la gloria, el rey le manda a su hija. Mientras él se prepara para ir a la boda, los mexicas sacrifican y desollan a la princesa, dando su piel a un joven para vestir. Cuando el padre llega, no ve a su hija; entra en el santuario del dios, está oscuro, le entregan una lámpara. Cuando logra ver al joven vistiendo la piel

\footnotetext{
Revista Iberoamericana, Vol. LXXVII, Núms. 236-237, Julio-Diciembre 2011, 849-863
ISSN 2154-4794 (Electrónico)
} 
de su hija y ese "horroroso espectáculo que tenía delante, se le conmovieron de dolor las entrañas y poseído de un tropel de violentos afectos salió como loco dando gritos a su gente y ordenando que tomasen venganza” (73). Pero todos tenían miedo y el padre “se volvió inconsolable a su ciudad a llorar su infortunio, lo restante de su vida" (73). ${ }^{15}$

Perfidia, lo tremebundo, sangre, horror, terror, oscuridad, llanto, gritos, dolor, violencia, venganza, poder corrupto... Todo lo sublime que se le pide a una historia romántica, a un "episodio brillante" en la "prosa comprometida” de una narración ficticia -o al menos ficcionalizada. ${ }^{16} \mathrm{Y}$ a través de este discurso dramático Clavijero desconstruye la noción sobrenatural de la diosa Toci, dejando ver que son seres humanos quienes inventan -con la materia prima de otro ser humano- una entidad política que va a llamarse Teteoinnan, Toci, abuela de los dioses, antepasada de Tonantzin, madre de los dioses (y con el tiempo, del dios Jesucristo, como la Virgen de Guadalupe-Tonantzin).

Entre otros episodios brillantes: la venganza de la esposa cuyo esposo, rey de los tlatelolcas, la golpea (116); el joven rey Nezahualpili que se salva la vida cambiando su ropa con uno de sus capitanes -el capitán muere y la escena ofrece un humor negro (119-20)-; Cholula: todo lo que Las Casas deja sin decir, Clavijero incluye para decir la historia completa -drama, colorido, punto de vista de los dos lados (323-29)-.

Recapitulo brevemente los marcadores fuertemente ficcionalizadores en la Historia de Clavijero: un punto de vista omnisciente que maneja bien la perspectiva sustitucionaria; el empleo abundante de comentarios narrativos y de diálogo; descripciones que a menudo coinciden con la exaltación del sublime y/o del tremendismo gótico.

Además de estas estrategias novelescas habría que mencionar cómo Clavijero 1) caracteriza a sus personajes principales, no solamente desinteresadamente con los hechos disponibles de la investigación, sino también con los rasgos morales y psicológicos de la especulación y análisis -o la imaginación-; 2) describe todo de manera más fuerte de lo que tiene que hacerlo (y qué bueno, porque si no, ¿cómo vamos a "ver” a los tlaxcaltecas que han sobrevivido la Noche Triste arrojarse sobre la tierra y "pacer la hierba que encontraban, implorando el amparo de sus dioses” [367]?); 3) no se olvida

${ }^{15}$ Sin aludir explícitamente a Toci, Sahagún comenta que "en muchas. . . cosas los diablos engañaron a vuestros antepasados y burlaron dellos, haciéndolos creer que algunas mujeres eran diosas y por tales las adoraban y reverentiaban" (72). Para un relato muy parecido, aunque sin el mismo grado de emotividad narrativa, véase a Durán (33-35) sobre "la muger de la discordia, [que]...ha de llamarse mi aguela ó madre, en el lugar donde emos de ir á morar” (33). El texto que sirviera de base para Durán, Clavijero y otros cronistas que narran el mismo episodio en la historia de los chichimecas-mexicas será el Códice Ramírez (21-23), sobre la mujer de la discordia, hija del rey de Culhuacán, cuyo sacrificio resulta en la creación de la diosa Toci.

${ }^{16}$ Para una maravillosamente romántica adaptación de un texto de por sí ya romántico, véase el poema "La princesa de Colhuacán” de José Joaquín Pesado (1801-1860). Los datos históricos que Pesado ornamenta siguen de cerca los que Clavijero relata; en el poema se destacan los pasajes claramente fabulados por su valor "sublime" y sentimentaloide. Presentar los dos textos juntos a los estudiantes de una clase de poesía ofrece una rica oportunidad histórico-literaria.

Revista Iberoamericana, Vol. LXXVII, Núms. 236-237, Julio-Diciembre 2011, 849-863
ISSN 2154-4794 (Electrónico) 
de que la nación consta de sus mujeres igual que sus hombres: a través de la Historia figuran muchas alusiones a aquéllas en roles activos y éstas incluyen no sólo a doña Marina: a ésta Clavijero caracteriza como "una joven noble, bella, piritosa y de buen entendimiento... [que] fue constantemente fiel y adicta a los españoles y de imponderable utilidad en la conquista... y cuyo nombre es tan célebre hasta ahora en aquel reino, no menos entre los mexicanos que entre los españoles” (299-300); ${ }^{17} 4$ ) enfatiza el heroísmo de los participantes tlaxcaltecas y otros indígenas en las batallas de la conquista, tanto los que se arriesgan la vida para salvar la de Cortés (392) como "un animoso tlaxcalteca" que ingenia un puente arbóreo para alcanzar al enemigo, seguido de Bernal Díaz del Castillo y cinco otros españoles (391). ${ }^{18}$

Se ha comentado la labor de rescate y repaso que Clavijero cumple con esta obra insigne. El encargado de la edición que manejo, Mariano Cuevas, asevera que, más que el narrador de la historia de México en el siglo XviII, Clavijero es su creador, porque aunque "había miles de fragmentos utilizables para esta gigantesca construcción" de "obra de conjunto, de partes bien trabadas y unidas, no había ninguna" (xii). La mayoría de las excelentes obras de las que se valió para sintetizar la historia más completa que se conocía hasta entonces no estaban publicadas todavía, y así es que el servicio que ofrece Clavijero es doblemente valioso. Triplemente, incluso, si podemos agregar a sus méritos como historia y como documento ejemplar disponible al público, el de obra emotiva y aún imaginativa que narra la historia nacional de los dos Méxicos en sus momentos primigenios. Éste es el fin instrumental de lo que será la novela histórica romántica de Occidente, y es la finalidad de las dos protonovelas que produce Clavijero: la del argumento medieval -la historia tolteca, chichimeca y mexica- y el renacentista -la historia de la conquista. Entre las dos, asienta las bases de la historia nacional de un México independiente de la peninsular y, consciente o no, demuestra las raíces mixtas

${ }^{17}$ Ya que Clavijero coteja todos los textos escritos y pintados sobre las historias indígenas y de la conquista, su Historia sale bien poblada de mujeres. Algunos ejemplos: leemos (o al menos yo leo) con alegre sorpresa que entre los ocho reyes toltecas de Tula el penúltimo fue mujer, la reina Xiuhtzaltzin (49); los habitantes de Mesoamérica siempre ofrecían mujeres para "firmar" un pacto, y no solamente a Cortés después de perder una batalla (55); la esposa del rey de Tlatelolco lo odia tanto, por golpearla, que se venga por revelar sus planes para atacar a México y luego lo abandona, llevándose a los cuatro hijos (116); María de Estrada, soldadera, lucha como hombre con lanza y rodela en la batalla de Otumba (368).

${ }^{18}$ La Historia de Clavijero, en especial las Disertaciones al final, participa espléndidamente en la polémica del Mundo Viejo-Nuevo Mundo instigada por escritores anti-americanos de la Iluminación; en nombre de la filosofía y la ciencia, hombres como Cornelius de Pauw, Georges-Louis Leclerc, comte de Buffon, y Guillaume-Thomas Raynal afirmaron que los nativos del Nuevo Mundo eran caníbales porque carecían de comida, que la sociedad de un clima tropical resultaba automáticamente inferior, que los hombres de tal sociedad eran afeminados y poco dispuestos a procrear, etc. Bastante más iluminado que aquellos pensadores etnocéntricos, Clavijero refuta sus argumentos al razonar con modernidad brillante -y no deja de darles a los "impugned Mexicans (Creoles as well as Indians)...a participatory voice in the defense of their own status as valid human beings" (Peterson 150)-.

Revista Iberoamericana, Vol. LXXVII, Núms. 236-237, Julio-Diciembre 2011, 849-863
ISSN 2154-4794 (Electrónico) 
de la nación criolla, mestiza e indígena, tanto racial como religiosa, pese al esfuerzo castellano por purificar la sociedad colonial por la conversión (o el genocidio).

Estas narraciones clavijeñas, ya épicas, ya patéticas, demuestran que por la misma conversión e inversión estratégica de carne femenina, entre naciones que buscan alianzas políticas o después de batallas que buscan pactar amistades, entre las razas indígenas y españolas, se iba gestionando una raza tercera y una creencia sincrética que un día iba a conformar el catolicismo popular. ${ }^{19}$ Muchas veces, en el torbellino de la historia remota, parece mentira lo que cuenta Clavijero acerca de las sucesivas naciones que iban llegando "como enjambres...a ocupar las tierras meridionales” de Anáhuac (52). En su momento estratégico, "salieron los mexicanos, no poco gustosos, de su cautiverio y se encaminaron hacia el norte de Colhuacán” (71). En la nueva ciudad de Tenochtitlan que no mucho después fundan con el sacrificio de un colhúa que por ahí caminaba (Clavijero 71; Torquemada 75-77), los mexicanos comenzaron una historia nacional basada en "los ensayos del bárbaro y execrable sistema de religión que después veremos”(Clavijero 73).

Con la ciudad de Tlaxcala, Tenochtitlan tiene una relación especial, las dos siendo fuentes de guerreros cautivos para el sacrificio, hecho nuclear para Clavijero, quien comenta más de una vez que si no fuera por la religión azteca basada en el sacrificio humano, los mexicanos habrían podido vencer a los conquistadores. En un momento dramático, "una gran multitud de enemigos” de Xochimilco por poco captura a Cortés cuando se le desmaya su caballo. En vez de matarlo, se empeñan en llevárselo para sacrificar. Es salvado por "un valiente tlaxcalteca," dos criados y otros españoles, a lo que sentencia Clavijero:

No hay duda de que así en ésta como en otras muchas ocasiones pudieran fácilmente dar la muerte a Cortés sus enemigos, si hubieran desistido del empeño de tomarle vivo para sacrificarlo a sus dioses. Esta fue sin duda una de las cosas que facilitaron a los españoles la conquista. (392)

Hay, además, lo que Clavijero caracteriza como una curiosa voluntad de morir. Llega el momento cuando está clarísimo que es imposible que los mexicanos ganen cualquier provecho en seguir peleando, pero ya que sus sacerdotes insisten que la ira de los dioses "se debía temer si se rendían a aquellos crueles enemigos de su religión, y cuya protección debían procurarse con oraciones y sacrificios” (408), prevaleció el dictamen religioso por sobre los consejos políticos y militares, y los mexicanos siguieron peleando y muriendo por millares. Del resultado más que trágico comenta Clavijero que pareciera que la religión azteca tenía tendencias suicidas. Seguro que

19 "En la América Latina rural, el catolicismo popular tiende a consistir en una combinación de elementos indígenas precolombinos, el catolicismo hispano popular del siglo xvı y las enseñanzas oficiales de la Iglesia” (Rowe y Schelling 86-87).

ISSN 0034-9631 (Impreso) 
las tenía autodestructivas y masoquistas: “[...] los que eran tan crueles con otros no es mucho que fuesen también inhumanos consigo mismos ... Trataban su [propia] carne como si fuera insensible y derramaban con tanta prodigalidad su sangre como si fuera un líquido superfluo del cuerpo” (174). El sacrificio opera como el talón de Aquiles de la nación y causa trágica de la pérdida de la autonomía del pueblo mexica. Éste es un final patético más de novela que de historia objetiva.

Las características nacionales de los mexicanos que Clavijero ilustra se unen a la nueva matriz nacional, mientras Cortés y los demás colonos comienzan a poblar la Nueva España; el capítulo número uno de aquel romance nacional que Clavijero dramatiza en la segunda de sus narraciones. En ella la carne femenina también está cambiada entre enemigos hechos aliados y la nueva raza sigue gestionando. Las alianzas entre tribus indias se reorganizan; Clavijero reserva capítulos de prosa particularmente emocionante, y con diálogo dramático de doña Marina, para el derrocamiento de los ídolos en Cempoala (309-11), la batalla de Cholula (325-28), las batallas épicas de la Noche Triste, incluyendo la batalla-crisis de Otumba (356-68).

Después de la caída de Tenochtitlan las luchas siguen, aunque con otra forma. Los aliados de Cortés, que no fueron vencidos, descubren que tienen que luchar duro para quedarse con lo que creían que no habían perdido. Una nación nueva de solicitantes, subalternos, aliados, jerarquías políticas y estructuras de poder es narrativizada de modo histórico, de modo romántico, de modo novelesco.

\section{OBRAS CITADAS}

Auerbach, Erich. Mimesis: The Representation of Reality in Western Literature. Willard R. Trask, trad. Princeton: Princeton UP, 1968.

Bakhtin, Mikhail. The Dialogic Imagination: Four Essays. Michael Holquist, ed. Caryl Emerson y Michael Holquist, trads. Austin: U of Texas P, 1981.

Problems of Dostoevsky's Poetics. Caryl Emerson, ed. y trad. Wayne C. Booth, intro. Minneapolis: U of Minnesota P, 1984.

Brushwood, John S. Genteel Barbarism: Experiments in Analysis of Nineteenth-Century Spanish-American Novels. Lincoln: U of Nebraska P, 1981.

Blanco, José Joaquín. Esplendores y miseria de los criollos: la literatura en la Nueva España. Tomo 2 de 2. México: Cal y Arena, 1989.

Cañizares-Esguerra, Jorge. How to Write the History of the New World: Histories, Epistemologies, and Identities in the Eighteenth-Century Atlantic World. Stanford: Stanford UP, 2001.

Castro Leal, Antonio. Prólogo. La hija del judío. Por Justo Sierra O’Reilly. Tomo 1 de 2. México: Porrúa, 1959. x-xvii.

Revista Iberoamericana, Vol. LXXVII, Núms. 236-237, Julio-Diciembre 2011, 849-863
ISSN 2154-4794 (Electrónico) 
Clavijero, Francisco Javier. Historia antigua de México. Mariano Cuevas, ed. 9ª ed. México: Porrúa, 1991.

Códice Ramírez. Siglo XVI. México: Secretaría de Educación Pública, 1975.

Cohn, Dorrit. "Signposts of Fictionality: A Narratological Perspective.” Poetics Today 11/4 (1990): 775-804.

Collini, Stefan, ed. Introducción. "Interpretation Terminable and Interminable." Interpretation and Overinterpretation. Por Umberto Eco, Richard Rorty, Jonathan Culler, y Christine Brooke-Rose. Cambridge: Cambridge UP, 1992. 1-21.

Durán, Fray Diego. Historia de las Indias de Nueva España. José F. Ramírez, ed. Tomo 1 de 2. México: J.M. Andrade y F. Escalante, 1867.

Eagleton, Terry. Literary Theory: An Introduction. Minneapolis: U of Minnesota P, 1983.

Egan, Linda. Carlos Monsiváis: cultura y crónica en el México contemporáneo. Isabel Vericat, trad. México: Fondo de Cultura Económica, 2004.

Carlos Monsiváis: Culture and Chronicle in Contemporary Mexico. Tucson: Arizona UP, 2001.

"Servando Teresa de Mier y su sátira general de las cosas de la Vieja España". Literatura Mexicana 15 (2004): 7-22.

Estrada, Oswaldo. La imaginación novelesca: Bernal Díaz entre géneros y épocas. Madrid: Iberoamericana; Frankfurt am Main: Vervuert, 2009.

Foley, Barbara. Telling the Truth: The Theory and Practice of Documentary Fiction. Ithaca: Cornell UP, 1986.

Green, Miranda J. The World of the Druids. London: Thames \& Hudson, 1997.

Hernadi, Paul. "Dual Perspective: Free Indirect Discourse and Related Techniques.” Comparative Literature 1 (1972): 32-43.

Hirsch, E.D., Jr. Validity in Interpretation. New Haven: Yale UP, 1967.

Ixtlilxóchitl, Fernando de Alva. Historia de la nación chichimeca. Germán Vázquez Chamorro, ed. Madrid: Dastin, 2000.

Jauss, Hans Robert. "Literary History as a Challenge to Literary Theory.” New Literary History 14 (1982-1983): 189-94.

Lanser, Susan Sniader. The Narrative Act: Point of View in Prose Fiction. Princeton: Princeton UP, 1981.

Meyer, Michael C. y William L. Sherman. The Course of Mexican History. $4^{a}$ ed. Nueva York: Oxford UP, 1991.

Mignolo, Walter. “'El metatexto’ historiográfico y la historiografía indiana”. Modern Language Notes 96 (1981): 358-402.

Pesado, José Joaquín. "La princesa de Colhuacán”. Obra literaria II. Poesía. Ed. Facsimilar de 1886. México: Universidad Nacional Autónoma de México, Secretaría de Cultura/Gobierno del Estado de Puebla, 2001. 227-32.

Revista Iberoamericana, Vol. LXXVII, Núms. 236-237, Julio-Diciembre 2011, 849-863
ISSN 2154-4794 (Electrónico) 
Peterson, Amy A. "Satyrs of the New World: Clavijero's Rebuttal to the Old World-New World Polemic.” Colonial Latin American Review 3 (1994): 139-58.

Pupo-Walker, Enrique. La vocación literaria del pensamiento histórico en América: desarrollo de la prosa de ficción: siglos XVI, XVII, XVIII y XIX. Madrid: Gredos, 1982.

Ragussis, Michael. "Writing Nationalist History: England, the Conversion of the Jews, and Ivanhoe.” ELN 60/1 (1993):181-215.

Rowe, William, y Vivian Schelling. Memoria y modernidad: cultura popular en América Latina. México: Grijalbo, 1991.

Sahagún, Fray Bernardino de. Historia general de las cosas de Nueva España. Tomo 1 de 2. Alfredo López Austin y Josefina García Quintana, eds. Madrid: Alianza, 1988.

Scholes, Robert, y Robert Kellogg. The Nature of Narrative. Londres: Oxford UP, 1966.

Sroka, Kenneth M. "The Function of Form: Ivanhoe as Romance.” Studies in English Literature, 1500-1900 18/4 (1979): 645-53.

Stoll, Anita K. “Clavijero, Francisco Javier.” Dictionary of Mexican Literature. Eladio Cortés, ed. Westport, CT: Greenwood, 1992. 173-77.

Torquemada, Fray Juan de. Monarquía indiana. Miguel León Portilla, ed. Tomo 1 de 3. México: Porrúa, 1969.

Unzueta, Fernando. "The Nineteenth-Century Novel: Toward a Public Sphere or a Mass Media?” Latin American Literature and Mass Media. Edmundo Paz-Soldán y Debra A. Castillo, eds. Nueva York: Garland, 2001. 21-40.

Walsh, Catherine Henry. "The Sublime in the Historical Novel: Scott and Gil y Carrasco.” Comparative Literature 42/1 (1990): 29-48.

Watt, Ian. The Rise of the Novel: Studies in Defoe, Richardson and Fielding. Berkeley: U of California P, 1964.

White, Hayden. The Content of the Form: Narrative Discourse and Historical Representation. Baltimore: Johns Hopkins UP, 1987.

Revista Iberoamericana, Vol. LXXVII, Núms. 236-237, Julio-Diciembre 2011, 849-863 ISSN 0034-9631 (Impreso) 
